\title{
Energetic Macroscopic Representation of a Naturally-Aspirated Engine coupled to a salient pole synchronous machine
}

\author{
J. Baert*, S. Jemei*, D. Chamagne*, D. Hissel*, S. Hibon**, D. Hegy** \\ * University of Franche-Comte, FEMTO-ST (Energy Department), UMR CNRS 6174, \\ 90010 Belfort, France (e-mail: jerome.baert@univ-fcomte.fr). \\ **Alstom Transport, 3 Avenue des Trois Chênes, 90000 Belfort, France \\ (e-mail: samuel.hibon@transport.alstom)
}

\begin{abstract}
Hybrid Electric Vehicle (HEV) is considered as the most promising solution to overcome energy crisis and air pollution. To insure an improvement of the vehicle performance and a decrease of pollutant emissions, the design of its powertrain components is necessary. In a project of a hybrid locomotive, the studied railway powertrain admits a diesel engine as a primary source. In this paper, a dynamic model of a Naturally-Aspirated Engine using Energetic Macroscopic Representation (EMR) is presented. To deliver the produced mechanical power to a central Direct Current (DC) bus, a salient pole synchronous machine EMR model is also presented. From EMR models, the Maximum Control Structure (MCS) and then a Practical Control Structure (PCS) to locally control the diesel driven generator set are implemented. In addition to control the power delivered by the system, consumption and $\mathrm{CO}_{2}$ gas emissions estimations are obtained from these models.
\end{abstract}

Keywords: Energetic Macroscopic Representation, Maximum Control Structure, naturally-aspired engine, synchronous machine, hybrid locomotive, energy, environment.

\section{INTRODUCTION}

Due to the inevitable drying up of petroleum reserves, the growing concerns on fuel efficiency and global "warning" (i.e. increase of pollutant emissions and potential increase of global temperature), the use of hybrid systems in vehicular technologies is constantly increasing. Indeed, hybrid vehicles are an essential bridge between oil-based vehicles and electric vehicles (Cousineau 2006). Even if it is a more ecological mean of transport than the air, road or maritime transport, the railway transport is also concerned with its diesel locomotives used for specific tasks (assistance mission, maintenance on catenaries...) (Akli 2007). The French local freight, which represents $40 \%$ of the global freight transport, is realized by private operators. They often leave from a nonelectrified junction and need to be energetically autonomous. The existing shunting activities are usually performed by locomotives powered by a noisy diesel engine and not stopping when the locomotive is idling. In its activities of locomotives innovation, Alstom Transportation is proposing an advanced solution by adding to the traditional diesel electric propulsion, a battery/ultra capacitors propulsion system, more respectful of the environment. One step of the project is to propose a Matlab/Simulink model of the global system architecture using EMR (Bouscayrol 2005), (Solano 2011).

The first studies about Internal Combustion Engines (ICEs) were realised in 1898 with (Meier 1898). Since then, notable improvements were realised. Engines present higher efficiencies with specific power output and have to respect the imposed emissions regulations (Rakopoulos 2008). The use of exhaust gas recirculation, exhaust gas after treatment and other achievements has contributed to the development of cleaner diesel engines (Heywood 1998). The development of engine models on simulation proposed in (Lipkea 1994), (Rakopoulos 1995) and (Rakopoulos 1998) permit to deal with the prediction of the engine exhaust emissions trends, with the analysis of gas reactions and formations in the engine and with the improvement of the efficiency of the used engine models in a cycle simulation. However, considering the EMR literature, most of the ICEs models are static ones and do not provide information about the type of fuel injected in. For instance, in (Lhomme 2004), a simple model is used for the ICE and is presented figure 1. In other words, to implement the mechanical behaviour of an ICE (mechanical torque depending on speed velocity of the shaft), cartographies are used. Thus, dynamics are neglected and this kind of model is generally associated with dynamic components such as electric filters, power electronics... This paper presents a dynamic EMR of a Naturally-Aspirated Engine coupled to a salient pole synchronous machine. The proposed model aims to include dynamics and to propose a speed control of the engine.

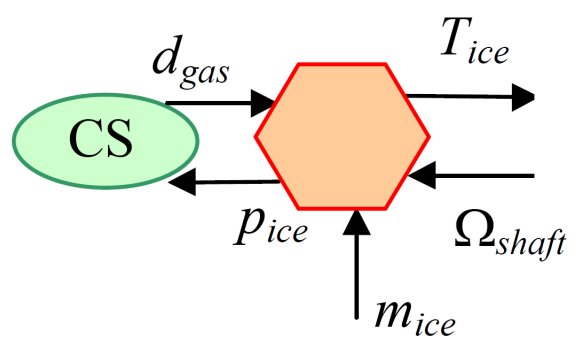

Fig. 1. EMR model of an ICE proposed in (Lhomme 2004) 


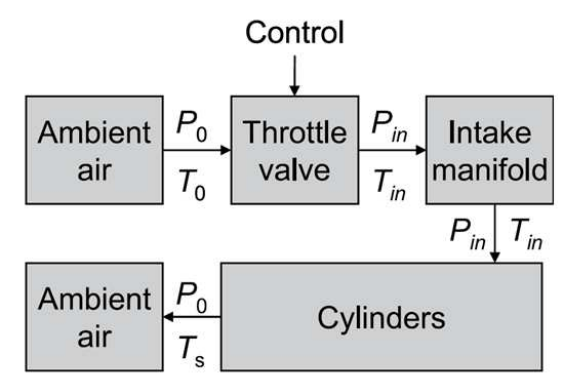

Fig. 2. General structure of a gasoline atmospheric engine (Verdonck 2010)

The atmospheric engine (Fig. 2) proposed in [Verd2010] is the adopted structure for this study. The next section 2 states about equations and EMR/MCS of the atmospheric engine. The section 3 describes the developed model of the salient pole synchronous machine to convert the mechanical power to electric power. Section 4 consists of merging sections 2 and 3 models with simulation results and their representation section 5 .

\section{EMR AND MCS OF THE ATMOSPHERIC ENGINE}

This section is dedicated to the EMR study of the presented atmospheric engine (Fig. 2). Thus, every part of the engine (ambient air, throttle valve, intake manifold and cylinders) is detailed.

\subsection{Ambient air (intake part)}

Ambient air is considered as a hydraulic source and characterised by a volume flow rate $\left(\dot{\mathrm{m}}_{\mathrm{air}}\right)$ and a pressure $\left(\mathrm{P}_{\mathrm{im}}\right)$.

\subsection{Throttle valve}

The throttle valve is not directly represented here. In that case, this element will be taken into account in the subsection 2.8 using MCS.

\subsection{Intake manifold}

The simulation models the intake manifold as a differential equation for the pressure. The difference in the incoming and outgoing mass flow rates represents the net rate of change of air mass with respect to time. This quantity, according to the ideal gas law, is proportional to the time derivative of the manifold pressure. Thus, it corresponds to an element of accumulation using the EMR formalism. With this approach the differential equation for the pressure $\mathrm{P}_{\mathrm{im}}$ in the volume $V_{\text {im }}$ is:

$$
\frac{d P_{i m}(t)}{d t}=\frac{R T_{i m}}{V_{i m}}\left(\dot{m}_{\text {air }}(t)-\dot{m}_{c y l}(t)\right)
$$

with $\mathrm{R}$, the ideal gas constant, $\dot{\mathrm{m}}_{\mathrm{air}}$ and $\dot{\mathrm{m}}_{\text {cyl }}$ represent the inlet and outlet mass flows respectively. In this model, the temperature is assumed as constant. As described in (Chrenko 2008), a gas flow presents at the same time thermal and pneumatic energies. A separation between these domains cannot be done. A change in the gas composition (chemical reaction consequence) changes the internal energy. Thus, the temperature is influenced too. If the choice of the variables does not comply with the general EMR approach (use of two variables), its application might be called pseudo-EMR and would need more than two variables.

\subsection{Fuel tank}

The fuel is considered as a hydraulic source too. In order to characterise the nature of fuel which is injected in cylinders, its heating value and more specifically its Lower Heating Value (LHV) in $\mathrm{J} / \mathrm{kg}$ is coupled with a mass flow rate $\left(\dot{\mathrm{m}}_{\text {fuel }}\right)$. The heating value or energy value of a substance, usually a fuel, is the amount of heat released during the combustion of a specified amount of it. The energy value is a characteristic for each substance. It is measured in units of energy per unit of the substance.

\subsection{Cylinders}

Cylinders mix the intake manifold air ( $\mathrm{P}_{\mathrm{im}}$ and $\dot{\mathrm{m}}_{\text {cyl }}$ variables $)$ and the fuel ( $\dot{\mathrm{m}}_{\text {fuel }}$ and LHV variables) provided by a tank. The reaction of combustion produces exhaust gases $\left(\dot{\mathrm{m}}_{\mathrm{exh}}\right.$ and $\mathrm{P}_{\text {air }}$ variables) and a mechanical power $\left(\mathrm{T}_{\text {cyl }}\right.$ and $\Omega_{\text {shaft }}$ variables). Because a hydraulic power is converted in a mechanical power, cylinders are represented by a multiphysics element of conversion. Equation (2) gives the mathematical expressions of the mechanical torque and the intake volume flow rate.

$$
\left\{\begin{array}{l}
T_{c y l}=\frac{1}{\Omega_{\text {shaft }}}\left(\eta_{\text {ind }} \dot{m}_{\text {fuel }} L H V-\frac{\Omega_{\text {shaft }}}{4 \pi} V_{e d}\left(P_{\text {air }}-P_{\text {im }}\right)\right) \\
\dot{m}_{c y l}=\frac{P_{i m}}{R T_{i m}} \eta_{v} \frac{\Omega_{\text {shaft }}}{4 \pi} V_{e d}
\end{array}\right.
$$

with $V_{\text {ed }}$ the engine displacement, $\eta_{\text {ind }}$ the global (fueltorque) efficiency and $\eta_{\mathrm{v}}$ the volumetric efficiency. The volume flow rate of exhaust gases $\left(\dot{\mathrm{m}}_{\mathrm{exh}}\right)$ is considered as the sum of the intake volume flow rate $\left(\dot{\mathrm{m}}_{\mathrm{cyl}}\right)$ with the fuel volume flow rate (initial fuel mass flow rate $\dot{\mathrm{m}}_{\text {fuel }}$ converted in volume flow rate using the density of the considered fuel).

\subsection{Ambient air (exhaust part)}

Ambient air is also considered as a hydraulic source.

\subsection{Mechanical shaft}

A mechanical shaft is required to transmit the mechanical power to the synchronous salient pole machine. Its EMR modelling is represented by an element of accumulation and takes into account: the inertia of the shaft $(\mathrm{J})$, the friction forces $\left(\mathrm{f}_{\text {shaft }}\right)$ (equation (3)).

$$
J \frac{d \Omega_{\text {shaft }}(t)}{d t}=T_{\text {cyl }}(t)-T_{\text {load }}(t)-f_{\text {shaft }} \Omega_{\text {shaft }}(t)
$$




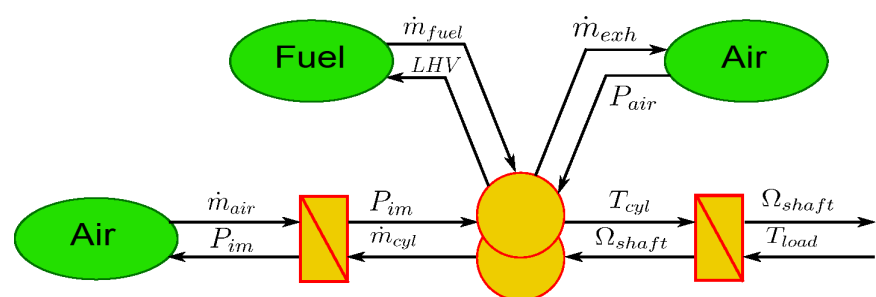

Fig. 3. EMR of the atmospheric engine

\subsection{MCS of the atmospheric engine}

The MCS' aim of the atmospheric engine is to control the rotational speed of the mechanical shaft. Thus, the use of a first PI controller permits to control the torque produced by the cylinders from the shaft speed reference. The difficulty of this tuning chain lies in the reversal of the cylinders' equations. A downstream coupling block must be reversed. This kind of block combines at least two inputs in a single output. In terms of control, a single reference has to induce two output references. In such a case, a distribution factor $\mathrm{k}_{\text {rep }}$ shares out the input reference $\left(\mathrm{T}_{\text {cyl }}\right.$ ref $)$ between the two

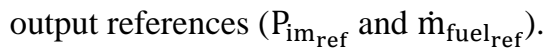

$$
\left\{\begin{array}{l}
P_{i m_{r e f}}=P_{a i r}+\frac{4 \pi}{V_{e d}}\left(1-k_{r e p}\right) T_{c y l_{r e f}} \\
\dot{m}_{\text {fuel }_{\text {ref }}}=\frac{1}{L H V \eta_{\text {ind }}} \Omega_{\text {shaft }} T_{c y l_{\text {ref }}} k_{\text {rep }}
\end{array}\right.
$$

The repartition factor value is set to 1 . Because the studied engine is an atmospheric engine, it means that the pressure in the intake manifold is equal to the air pressure. Setting $\mathrm{k}_{\mathrm{rep}}$ equal to one, equation (4) implies $\mathrm{P}_{\mathrm{im}} \mathrm{ref}=\mathrm{P}_{\mathrm{air}}$ and equation (5).

$$
\dot{m}_{\text {fuel }_{\text {ref }}}=\frac{1}{L H V \eta_{\text {ind }}} \Omega_{\text {shaft }} T_{c y l_{\text {ref }}}
$$

Finally, a second PI controller controls the air flow to impose ( $\left.\dot{\mathrm{m}}_{\mathrm{air}_{\mathrm{ref}}}\right)$.

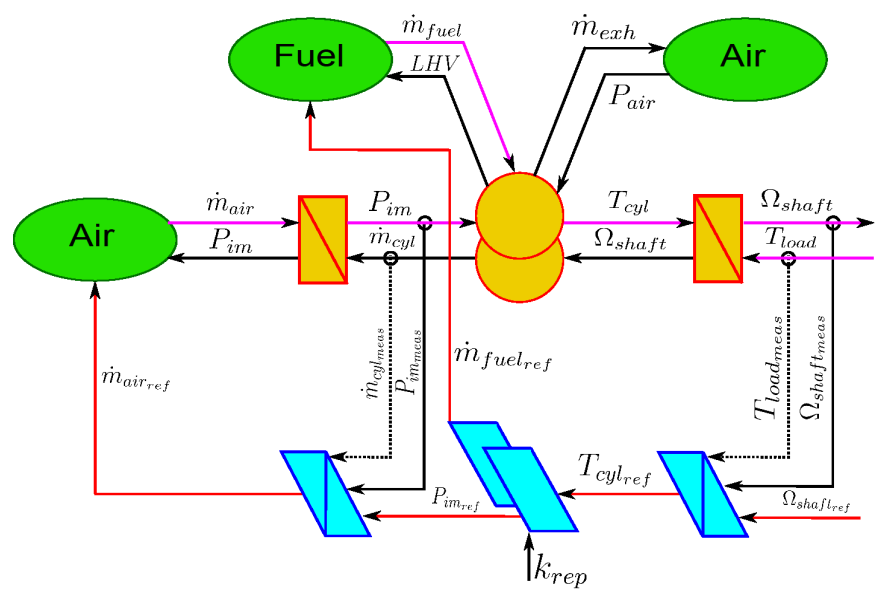

Fig. 4. MCS of the atmospheric engine

\section{EMR AND MCS OF THE ALTERNATOR}

\subsection{The $d-q$ synchronous reference frame}
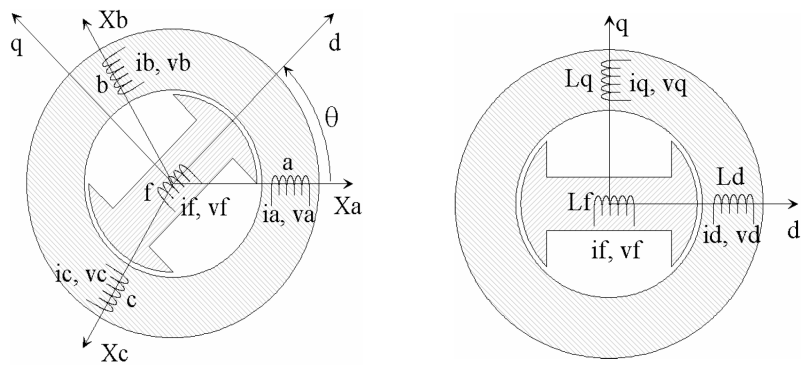

Fig. 5. Model of the synchronous machine in the three phase frame (left side) and Park frame (right side)

Equations which govern a three phase alternative machine depend on resistances, inductances and mutual inductances of its rotor and its stator. Those mutual inductances are linked to the relative position of the rotor with the stator. Thus, to simplify differential equations, it is easier to work in the d-q frame than in the three phase one. To obtain a constant mutual inductance, Concordia and Park transformations are used. It permits to express the three currents, voltages and flux of the stator $\left(a_{s}, b_{s}, c_{s}\right.$ frame $)$ and of the rotor $\left(a_{r}, b_{r}, c_{r}\right.$ frame) in a frame linked to the rotary field ( $\mathrm{d}-\mathrm{q}$ frame). Considering voltages, currents and flux three phase components as $\mathrm{X}_{\mathrm{a}}, \mathrm{X}_{\mathrm{b}}, \mathrm{X}_{\mathrm{c}}$ and as $\mathrm{X}_{\mathrm{d}}, \mathrm{X}_{\mathrm{q}}$ in the $\mathrm{d}-\mathrm{q}$ frame, Park (equation 1) and Concordia transformations permit to work in the two frames.

$$
\left[\begin{array}{l}
X_{d} \\
X_{q}
\end{array}\right]=\sqrt{\frac{2}{3}}\left[\begin{array}{ccc}
\cos (\theta) & \cos \left(\theta-\frac{2 \Pi}{3}\right) & \cos \left(\theta+\frac{2 \Pi}{3}\right) \\
-\sin (\theta) & -\sin \left(\theta-\frac{2 \Pi}{3}\right) & -\sin \left(\theta+\frac{2 \Pi}{3}\right)
\end{array}\right]\left[\begin{array}{c}
X_{a} \\
X_{b} \\
X_{c}
\end{array}\right]
$$

\subsection{Equations and EMR of the salient pole synchronous machine}

The machine corresponds to the figure 5 in the three phase frame (left side) and in the Park frame (right side). Equations 7,8 and 9 are the electromechanical torque $\mathrm{T}_{\text {load }}$, the magnetic flows $\left(\phi_{\mathrm{d}}, \phi_{\mathrm{q}}\right.$ and $\left.\phi_{\mathrm{f}}\right)$ and the voltages $\left(\mathrm{V}_{\mathrm{d}}, \mathrm{V}_{\mathrm{q}}\right.$ and $V_{f}$ ) equations of the electric machine depending on the shaft rotational speed $\Omega_{\text {shaft }}$, armatures resistances $\left(R_{s}\right.$ and $\left.R_{f}\right)$ inductances $\left(\mathrm{L}_{\mathrm{d}}, \mathrm{L}_{\mathrm{q}}\right.$ and $\left.\mathrm{L}_{\mathrm{f}}\right)$, mutual inductance $(\mathrm{M})$ and the number of pole pair $(\mathrm{P})$.

$$
\begin{aligned}
& T_{\text {load }}=p\left(\Phi_{d} I_{q}-\Phi_{q} I_{d}\right) \\
& \left\{\begin{array}{l}
\Phi_{d}=L_{d} I_{d}+M I_{f} \\
\Phi_{q}=L_{q} I_{q} \\
\Phi_{f}=L_{f} I_{f}+M I_{d}
\end{array}\right.
\end{aligned}
$$




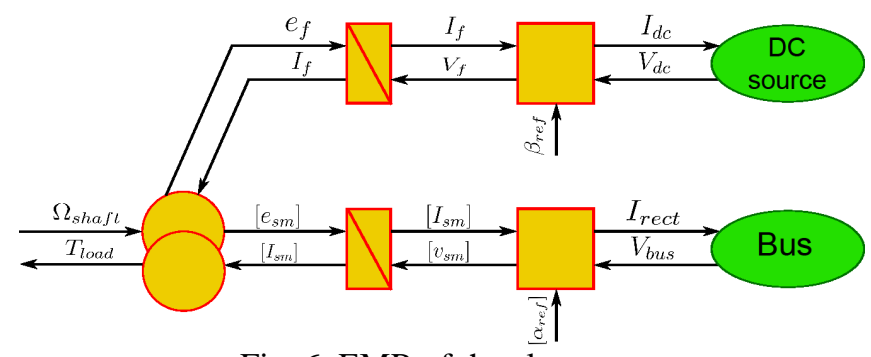

Fig. 6. EMR of the alternator

$$
\left\{\begin{array}{l}
V_{d}=R_{s} I_{d}+\frac{d \Phi_{d}}{d t}-\Omega_{\text {shaft }} \Phi_{q} \\
V_{q}=R_{s} I_{q}+\frac{d \Phi_{q}}{d t}+\Omega_{\text {shaft }} \Phi_{d} \\
V_{f}=R_{f} I_{f}+\frac{d \Phi_{f}}{d t}
\end{array}\right.
$$

From equations (7) and (8), electromotive forces $\left(\mathrm{e}_{\mathrm{d}}\right.$ and $\mathrm{e}_{\mathrm{q}}$ ) are expressed (equation (10)).

$$
\left\{\begin{array}{l}
e_{d}=-\Omega_{\text {shaft }} L_{q} I_{q}+M \frac{d I_{f}}{d t} \\
e_{q}=\Omega_{\text {shaft }}\left(L_{d} I_{d}+M I_{f}\right)
\end{array}\right.
$$

Interdependence between $\mathrm{d}$ and $\mathrm{q}$ axis variables clearly appears. Thus, using temporary variables $\left(\mathrm{V}_{\mathrm{d}}^{\prime}\right.$ and $\left.\mathrm{V}_{\mathrm{q}}^{\prime}\right), \mathrm{V}_{\mathrm{d}}$ $\left(\mathrm{V}_{\mathrm{q}}\right)$ voltage can be defined as the sum of $\mathrm{V}_{\mathrm{d}}^{\prime}\left(\mathrm{V}_{\mathrm{q}}^{\prime}\right)$ and $\mathrm{e}_{\mathrm{d}}$ $\left(\mathrm{e}_{\mathrm{q}}\right)$ voltages. From this operation, currents' dynamics are modelled under a transfer function form (equation 11).

$$
\left\{\begin{array}{l}
\frac{I_{d}(s)}{V_{d}^{\prime}(s)}=\frac{1}{R_{s}} \frac{1}{1+\frac{L_{d}}{R_{s}} s} \\
\frac{I_{q}(s)}{V_{q}^{\prime}(s)}=\frac{1}{R_{s}} \frac{1}{1+\frac{L_{q}}{R_{s}} s}
\end{array}\right.
$$

The same work is realised to solve the $d-q$ coupling in $f$ frame.

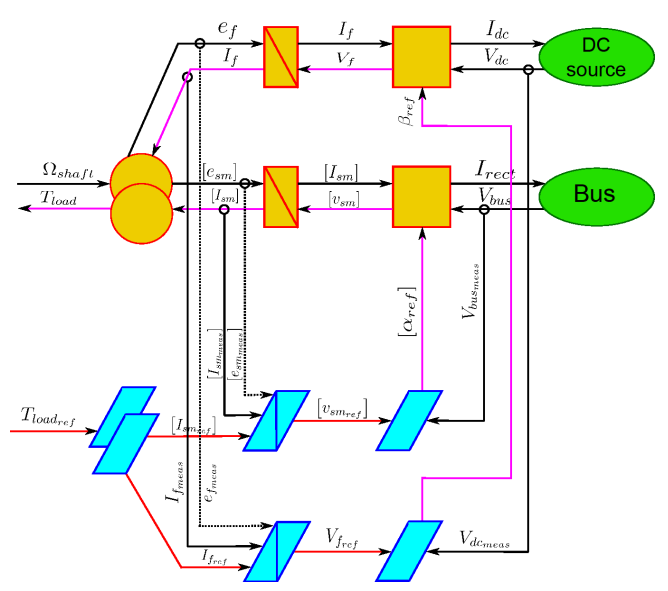

Fig. 7. MCS of the alternator

\subsection{MCS of the salient pole synchronous machine}

The goal of the alternator MCS is to control the torque ( $\left.\mathrm{T}_{\text {load }}\right)$ using the two available degrees of freedom $\left(\beta_{\text {ref }}\right.$ and $\left.\left[\alpha_{\text {ref }}\right]\right)$. The control chain is deduced from the setting chain. Thus, MCS presents an element of repartition to share out currents' references. The problem of this bloc is to obtain three references (currents) from one reference (torque). In reality, the torque is not the only reference to be imposed. Magnetic flux $\left(\phi_{\mathrm{d}}\right.$ and $\left.\phi_{\mathrm{q}}\right)$ are also imposed and coupled with the torque to deduce the three currents' references. The principle is to take the defluxing characteristic of the machine and to work on its maximum flux ( $\phi_{\text {ref }}$, equation 12).

$$
I_{r e f}=\frac{T_{\text {load }_{r e f}}}{p \phi_{\text {ref }}}
$$

The real flux ( $\phi$, equation 13) is a combination of the magnetic flux along $\mathrm{d}-\mathrm{q}$ axis.

$$
\phi=\sqrt{\phi_{d}^{2}+\phi_{q}^{2}}
$$

Taking into account the load angle $\delta$, windings' currents along $\mathrm{d}$ and $\mathrm{q}$ axis and inductor's current references are deduced thanks to equation 14 .

$$
\left\{\begin{array}{c}
I_{d_{r e f}}=-I_{r e f} \sin \delta \\
I_{q_{r e f}}=I_{r e f} \cos \delta \\
I_{f_{r e f}}=\frac{\sqrt{\phi_{r e f}{ }^{2}-\left(L_{q} I_{r e f}\right)^{2}}-L_{q} I_{d_{r e f}}}{M}
\end{array}\right.
$$

Three PI controllers permit to control three voltages $\left(V_{d}, V_{q}\right.$ and $V_{f}$ ) from three currents $\left(I_{d}, I_{q}\right.$ and $\left.I_{f}\right)$. Finally, the inversion of rectifiers result in the control of transformation ratios, degrees of freedom of the system.

\subsection{Estimation of the load torque and the electromotive forces}

Because electromotive forces cannot be directly measured and because of the torque sensors' cost, a block of estimation (figure 8 ) is used to estimate $\left[\mathrm{e}_{\mathrm{dq}}\right], \mathrm{e}_{\mathrm{f}}$ and $\mathrm{T}_{\text {load }}$. Concerned equations are equations 7 and 10.

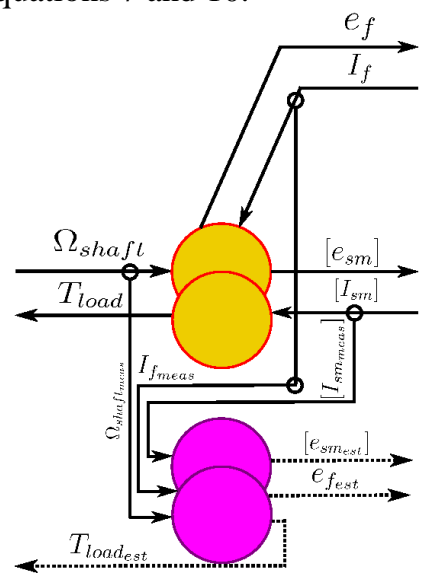

Fig. 8. Estimation of the load torque and the electromotive forces 


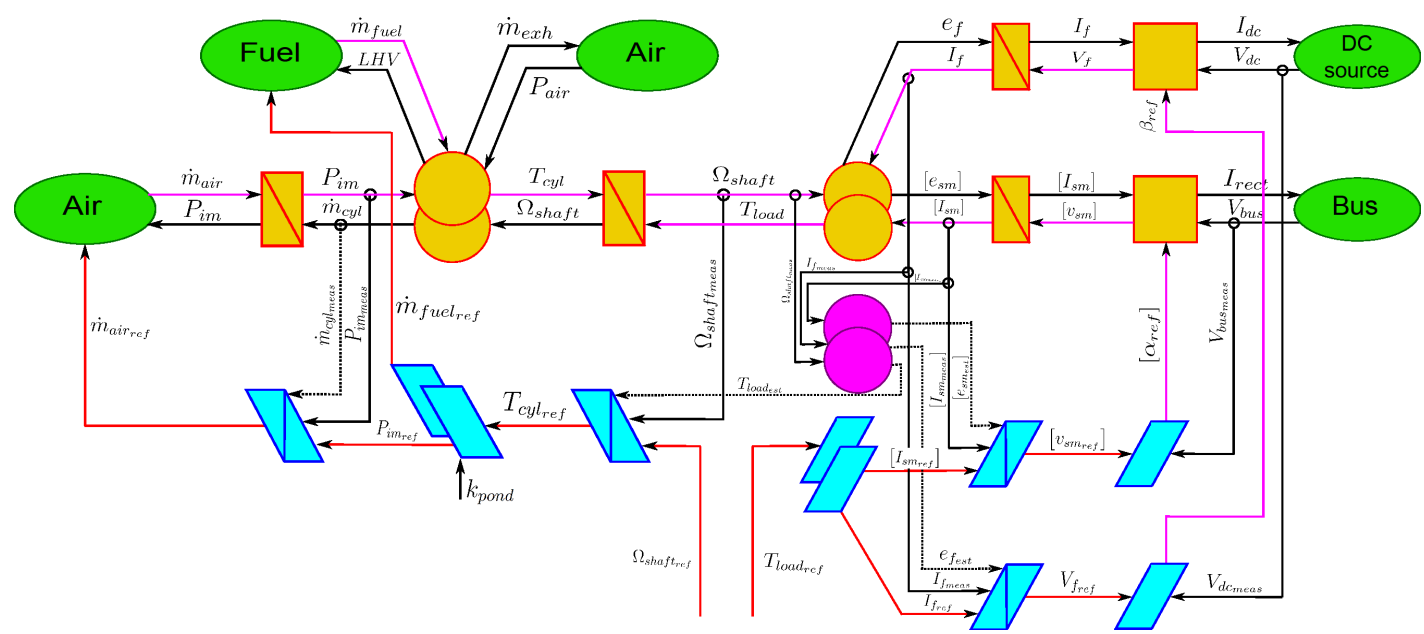

Fig. 9. EMR and PCS of the ICE

\section{EMR AND MCS OF THE ICE}

The diesel driven generator EMR is made up of the two previous presented models developed on figures 4 and 7 . The control of the mechanical power at the output of the shaft permits to control the electrical power delivered by the synchronous machine, depending on its losses.

\section{RESULTS}

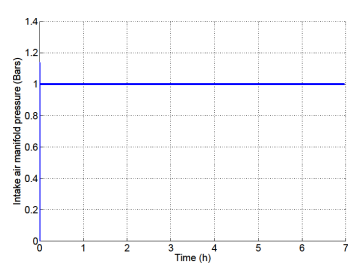

Fig. 10. Evolution of the intake air pressure according to time

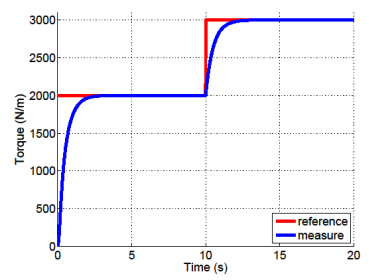

Fig. 12. Evolution of the mechanical torque of the shaft according to a reference

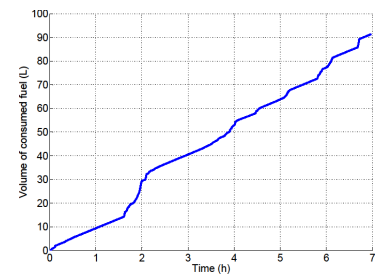

Fig. 14. Evolution of the fuel consumption according to time

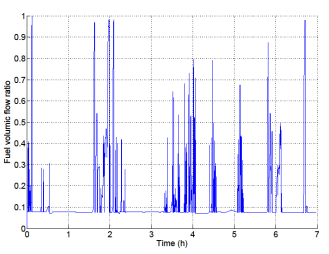

Fig. 11. Evolution of the fuel volume flow ratio according to time

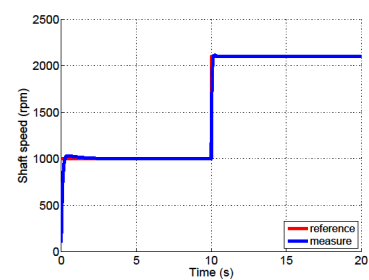

Fig. 13. Evolution of the rotational speed of the shaft according to a reference

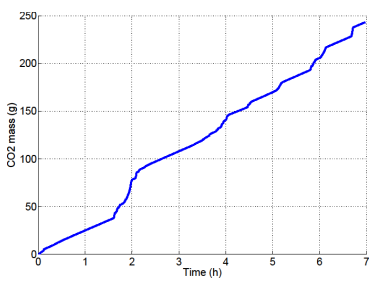

Fig. 15. Evolution of the $\mathrm{CO}_{2}$ mass product according to time

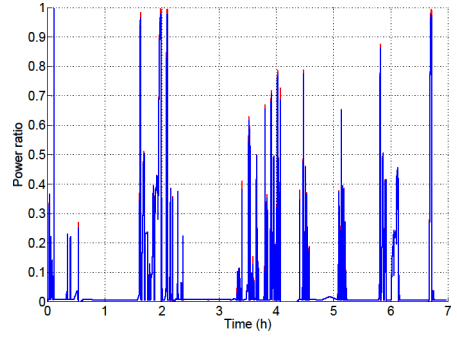

Fig. 16. Evolution of the power mission reference ratio (red) and the electric power ratio (blue) according to time

Presented results on figures 10 to 16 were obtained using the most restricting mission as an input. The results of the figure 10 permit to confirm that the pressure of the air into the intake manifold is equal to 1 bar like in a real atmospheric engine. Figures 11, 14 and 15 give an approximation of:

- the volume flow of the fuel at the intake,

- the corresponding volume of fuel used,

- the mass of exhaust carbon dioxide gas during the mission.

The volume of fuel is obtained thanks to an integration of the volume flow at the intake. From this volume (around 90L), the $\mathrm{CO}_{2}$ mass product is deduced. Indeed, one litre of fuel produces around $2.662 \mathrm{~kg}$ of $\mathrm{CO}_{2}$. Thus, around $250 \mathrm{~kg}$ of $\mathrm{CO}_{2}$ are emitted for the considered power mission. Moreover, the figure 16 informs that the mechanical power mission of reference is converted into an electric power provided to the central DC bus thanks to the synchronous machine. To check the good efficiency of the control of the ICE, a mechanical torque and a rotational speed references were applied to the shaft. On figures 12 and 13, references and model responses are represented in accordance with the key.

\section{CONCLUSIONS}

In this paper, a novel EMR/MCS/PCS modelling of a diesel driven generator set has been proposed. Implemented models using Matlab/Simulink take into account:

- the dynamics of a naturally aspired engine and of a salient pole synchronous machine,

- the nature of the used fuel using its LHV, 
- estimations of the $\mathrm{CO}_{2}$ mass product and the consumption of fuel of the atmospheric engine,

- a control of the mechanical power and indirectly the electrical power delivered depending on the alternator losses.

Presented simulation results and their interpretation in the results section prove the good effectiveness of the realised work. The model will be integrated in the global architecture of the hybrid locomotive as a primary source with dynamical batteries and ultra-capacitors EMR models. A future energy management strategy of the system to share out power demand of the vehicle between sources has to be developed. Contrary to actual energy management strategies based on a static model of the ICE, this one will have to take into account dynamical behaviours of the ICE.

\section{REFERENCES}

Akli, C., Roboam, X., Sareni, B. and Jeunesse, A. (Akli 2007). Energy management and sizing of a hybrid locomotive. European Conference on Power Electronics and Applications, pp. 1 -10, 2007.

Bouscayrol, A., Delarue, P. and Guillaud. X. (Bouscayrol 2005). Power strategies for maximum control structure of a wind energy conversion system with a synchronous machine. Renewable Energy, Vol. 30, No. 15, pp. 2273-2288.

Chrenko, D. (Chrenko 2008). Energetic Macroscopic Representation Modeling and Control of a Low Temperature Fuel Cell System Fed by Hydrocar-

Bons. PhD thesis of UFC \& UTBM.

Cousineau, R. (Cousineau 2006). Development of a hybrid switcher locomotive the railpower green goat. IEEE Instrumentation Measurement Magazine, vol. 9, no. 1, pp. 25-29.

Eriksson, L. (Eriksson 2007). Modeling and Control of Turbocharged SI and DI Engines. Oil Gas Science and Technology. Rev. IFP, Vol. 62, No. 4, pp. 523-538.

Heywood, JB. (Heywood 1998). Internal combustion engine fundamentals. New York: McGraw-Hill.

Lhomme, W., Bouscayrol, A. and Barrade, P. (Lhomme 2004). Simulation of a Series Hybrid Electric Vehicle based on Energetic Macroscopic Representation. IEEE International Symposium on Industrial Electronics, Ajaccio, France, pp. 1-6.

Lipkea, WH., DeJoode, A.D. (Lipkea 1994). Direct injection diesel engine soot modeling: formulation and results. SAE. Paper no. 940670.

Meier, E.D. (Meier 1898). Diesel's rational heat motor. Journal of the Franklin Institute, Volume 146, Issue 4, Pages 241-264.

Rakopoulos, C.D., Hountalas, D.T., Taklis, G.N. and Tzanos, E.I. (Rakopoulos 1995). Analysis of combustion and pollutants formation in a direct injection diesel engine using a multi-zone model. Energ Res 19:63-88.

Rakopoulos, C.D., Hountalas, D.T. (Rakopoulos 1998). Development and validation of a 3D multi-zone combustion model for the prediction of DI diesel engines performance and pollutants emissions. Trans SAE, J Engines, 107, pp. 1413-29.
Rakopoulos, C.D., Antonopoulos, K.A., Rakopoulos, D.C. and Hountalas, D.T. (Rakopoulos 2008). Multi-zone modeling of combustion and emissions formation in DI diesel engine operating on ethanol-diesel fuel blends. Energy Conversion and Management, Volume 49, Issue 4, Pages 625-643.

Solano-Martinez, J., Hissel, D., Pera, M.C., Amiet, M. (Solano 2011). Practical Control Structure and Energy Management of a Test Bed Hybrid Electric Vehicle. IEEE Transactions on Vehicular Technology, vol. PP, no. 99, pp. 1,0 .

Verdonck, N., Chasse, A., Pognant-Gros, P. and Sciarretta, A. (Verdonck 2010). Automated Model Generation for Hybrid Vehicles Optimization and Control. Oil Gas Sci. Technol. Rev. IFP, Vol. 65, No. 1, pp. 115-132.

Appendix A. EMR SYNOPTIC

\begin{tabular}{|c|c|}
\hline Energy source & Strategy \\
\hline Estimator & $\begin{array}{l}\text { Mono-physical domain } \\
\text { converter }\end{array}$ \\
\hline $\begin{array}{l}\text { Multi-physical domain } \\
\text { converter }\end{array}$ & $\begin{array}{c}\text { Energy accumulation } \\
\text { element }\end{array}$ \\
\hline $\begin{array}{l}\text { Adjustable mono-physical } \\
\text { converter }\end{array}$ & $\begin{array}{l}\text { Mono-physical domain } \\
\text { coupling }\end{array}$ \\
\hline $\begin{array}{l}\text { Multi-physical domain } \\
\text { coupling }\end{array}$ & $\begin{array}{l}\text { Mono- and multi-physical } \\
\text { domain coupling inverter }\end{array}$ \\
\hline $\begin{array}{l}\text { Mono- and multi-physical } \\
\text { domain converter inversion }\end{array}$ & $\begin{array}{l}\text { Energy accumulation } \\
\text { inversion (controller) }\end{array}$ \\
\hline
\end{tabular}

